\title{
La utilidad del patrimonio documental español para la re- construcción de la historia del clima y su incidencia en la sociedad
}

\section{The utility of Spanish documentary heritage for the recon- struction of the history of the climate and its impact on so- ciety}

\author{
Francisco Saulo Rodríguez Lajusticia
}

Universidad de Cantabria

Departamento de Historia moderna y contemporánea

Facultad de Filosofía y Letras. Edificio Interfacultativo

Avda. de los Castros, 52. 39005 - Santander

rodriguezfs@unican.es

ORCID: https://orcid.org/0000-0002-9194-8360

Fecha de envío: 12/07/2018. Aceptado: 19/10/2018.

Referencia: Santander. Estudios de Patrimonio, 1 (2018), pp. 155-180.

ISSN 2605-4450 (ed. impresa) / ISSN 2605-5317 (digital)

Este trabajo se enmarca en las líneas de trabajo del grupo de investigación SIGYDOC: Signos y documentos. Cultura escrita y sociedad en Aragón (siglos XII-XVIII), de la Universidad de Zaragoza y reconocido por el Gobierno de Aragón (referencia H15_17D)

Resumen: La reconstrucción del clima en el pasado se ha realizado recurriendo a gran cantidad de técnicas tales como el carbono 14, el análisis de sedimentos, la paleobotánica, la paleozoología... Frente a todo esto, el patrimonio documental español es extremadamente rico en datos sobre sequías, riadas, inundaciones, tormentas, terremotos... no sólo de España, sino de prácticamente todo el planeta. No siempre lo suficientemente explotado, este artículo pretende mostrar las enormes posibilidades que dicho patrimonio ofrece para conocer el clima del pasado y su incidencia en la sociedad desde la Edad Media hasta la actualidad.

Palabras clave: Clima; historia; reconstrucción; documentación; sequías; riadas; tormentas; terremotos.

\begin{abstract}
The reconstruction of the climate in the past has been made using a lot of techniques such as carbon 14, sediment analysis, paleobotany, paleozoology ... In contrast to all this, the Spanish documentary heritage is extremely rich in data on droughts, floods, storms, earthquakes... not only concerning to Spain, but also almost the entire planet. Not always sufficiently explored, this article intends to show the enormous possibilities that this heritage offers to know the climate of the past and its impact on society from the Middle Ages to the present.
\end{abstract}

Keywords: Climate; History; reconstruction; documentation; droughts; floods; storms; earthquakes. 
No cabe ninguna duda de la especial incidencia que el clima ha tenido en el devenir de determinados acontecimientos históricos. Quizá nunca la única causa que permite explicarlos, lo cierto es que, en muchas ocasiones, los historiadores han mostrado una excesiva tendencia a infravalorar o incluso a olvidar el contexto físico en el que tuvieron lugar dichos acontecimientos.

Cuando se repasa la historia de la humanidad, el clima ha tenido un insospechado protagonismo en más de una ocasión y así lo pone de manifiesto la cada vez más abundante bibliografía específica que hay sobre el tema.

Por citar algunos casos paradigmáticos, a nadie se le oculta la importancia que tuvieron en la antigua Roma las erupciones del Etna y del Vesubio, especialmente en el caso de este segundo volcán responsable de la destrucción de ciudades como Pompeya o Herculano.

Del mismo modo, diversos especialistas destacan cómo la sequía prolongada y la aridez creciente de las estepas asiáticas habrían sido factores determinantes en las migraciones hacia Occidente de hunos y ávaros ${ }^{1}$, responsables los primeros de acelerar la caída del Imperio Romano de occidente y los segundos de haber constituido un importante elemento desestabilizador en Europa oriental hasta su sometimiento definitivo por parte de Carlomagno.

De igual modo, las sequías que se produjeron en el norte de África en diversos momentos de los siglos VIII y IX y el hecho de que fueran mucho más acusadas que en la Península Ibérica habrían provocado, en opinión de Inocencio Font, las invasiones musulmanas de los años 757 y 873², mientras que Alain Ducellier ha resaltado cómo la erupción volcánica producida en la isla de Santorini en 726 o el terremoto acontecido en 740 en la Península Balcánica fueron utilizados por la dinastía isáurica bizantina como fenómenos indicativos de la cólera de Dios que le permitían implantar la prohibición de la adoración de las imágenes religiosas y dar pie con ello a la querella iconoclasta ${ }^{3}$.

1 COOK, Edward R., "Megadroughts, ENSO, and the Invasion of Late-Roman Europe by the Huns and Avars", en HARRIS, William V. (ed.), The Ancient Mediterranean Environment between Science and History, Leiden-Boston, Brill, 2013, p. 89.

2 FONT TULLOT, Inocencio, Historia del clima de España. Cambios climáticos y sus causas, Madrid, Instituto Nacional de Meteorología, 1988, p. 56.

3 DUCELLIER, Alain, "Les tremblements de terre balkaniques au Moyen Âge: as- 
La importancia del tiempo atmosférico y/o de diversas inclemencias completamente inesperadas en determinados acontecimientos históricos han sido resaltadas hasta la saciedad por parte de aquellos que han escrito sobre temas tales como la Armada Invencible y su frustrado intento de conquistar Inglaterra para destronar a Isabel I en 1588 o como los fracasos de Napoleón Bonaparte o de Adolf Hitler en sus campañas militares contra Rusia.

Más allá de los acontecimientos históricos "famosos" que, por lo general, son conocidos por todo el mundo, el clima también se encuentra detrás de los grandes contextos que los explican.

Que un deterioro acusado de las condiciones meteorológicas desencadenó y trajo consigo no pocos efectos negativos en la economía europea de los siglos XIV y XVII, tal y como explicaba Emmanuel Le Roy Ladurie, es algo de lo que prácticamente nadie duda hoy en día ${ }^{4}$. A día de hoy, los especialistas siguien coincidiendo en que las anomalías climáticas que se produjeron en el pasado constituyeron la causa de fondo de múltiples fenómenos, como, entre muchos ejemplos, destaca Andreas Rüther al hablar del empeoramiento del tiempo como desencadenante de las hambrunas y de las migraciones de los siglos XIII y, especialmente, XIV .

$\mathrm{Si}$, por el contrario, despegamos nuestra mirada de lo general y la centramos en lo más concreto que podamos imaginar hasta rozar incluso con el nivel de lo anecdótico, encontraremos también no pocas evidencias de la influencia del clima en el devenir humano. Así, por ejemplo, tan sólo el año 1816 cuenta con sendos estudios por haberse producido en el mismo una total ausencia de temperaturas veraniegas ${ }^{6}$.

pects matériels et mentaux", en BENNASSAR, Bartolomé (ed.), Les catastrophes naturelles dans l'Europe médiévale et moderne, Toulouse, Presses Universitaires du Mirail, 1996, pp. 64-65.

4 LE ROY LADURIE, Emmanuel, Histoire du climat depuis l'an mil, París, Flammarion, 1983, vol. I, p. 12.

5 RÜTHER, Andreas, "The role of climate and famine in the Medieval Eastern expansion", en COLLET, Dominik y SCHUH, Maximiliam (eds.), Famines during the 'Little Ice Age' (1300-1800). Socionatural entanglements in premodern societies, Cham, Springer, 2018, p. 134.

6 Entre una larga lista, véase por ejemplo KLINGAMAN, William K. y KLINGAMAN, Nicholas P., The year without summer: 1816 and the volcano that darkened the 
Así por ejemplo también, Geoffrey Parker destaca cómo "en la República de Holanda, fue tanta la nieve caída en marzo de 1651 que el funeral de Estado del estatúder Guillermo II tuvo que aplazarse debido a que los dolientes no podían llegar a La Haya, y luego la combinación de nieve derretida y una sucesión de tormentas causaron las peores inundaciones sufridas en ochenta años en las regiones del litoral"7.

En definitiva, y aunque los historiadores no siempre le han concedido la importancia que sin duda merece, es evidente que el clima ha sido un factor determinante para entender el comportamiento de los seres humanos, tanto a gran escala como a pequeña. Una aproximación a la reconstrucción de dicho clima y la especial utilidad que para ello tiene el patrimonio documental español constituye el tema central que abordaré a continuación.

\section{LA Climatología históRica Y La importancia CONCEDida AL PA- TRIMONIO DOCUMENTAL}

El punto en el que se encontraban en la primera década del siglo XXI los estudios de climatología histórica en España fue convenientemente abordado por un equipo multidisciplinar de varias instituciones hace poco más de diez años ${ }^{8}$, por lo que - máxime, no siendo yo especialista en el tema - no realizaré un estado de la cuestión al uso como, posiblemente, sería preceptivo elaborar.

world and changed History, Nueva York, St. Martin's Press, 2013.

7 PARKER, Geoffrey, El siglo maldito. Clima, guerras y catástrofes en el siglo XVII, Barcelona, Planeta, 2013, p. 46.

8 CREUS, José; PEÑA, José Luis; BARRIENDOS, Mariano; MORENO, Ana; GONZÁLEZ, Penélope; SANCHO, Carlos; VALERO, Blas; PÉREZ, Augusto; SAZ, Miguel A. y CONSTANTE, Ana, "Los estudios de Paleoclimatología en España”, en CUADRAT PRATS, José María y MARTÍN VIDE, Javier (eds.), La Climatología española. Pasado, presente y futuro, Zaragoza, Prensas Universitarias de Zaragoza, 2007, pp. 249-262 en español y 263-281 en inglés. Véase, en especial, el apartado 4, en el que los autores, remontándose al siglo XIX con los trabajos del médico y físico Manuel Rico, realizan un preciso recorrido por las principales aportaciones desde él hasta finales de los años noventa del siglo XX con autores tales como José María Fontana, Luis M. Albentosa, José Antonio Álvarez, Inocencio Font, Miguel Grimalt, Mariano Barriendos o Fernando Sánchez. De igual manera, los autores destacaban los trabajos que se estaban llevando a cabo entonces en las Universidades de Alicante, Almería, Barcelona, Complutense de Madrid y Zaragoza. 
Los instrumentos de los que disponemos para elaborar la historia del clima han sido también bien sintetizados por los especialistas. Así, por ejemplo, Wolfgang Behringer divide las fuentes para ello en dos grandes grupos: en primer lugar, las que se encuentran en lo que él llama "el archivo del planeta Tierra" y que serían los datos que pueden aportar técnicas tales como las que emplean isótopos (especialmente, los radiactivos), el análisis de sedimentos, la paleobotánica, la paleozoología, la perforación de capas de hielo, el estudio de los glaciares, la termoluminiscencia, la palinología, la dendroclimatología...; en segundo lugar, lo que él llama "el archivo de la sociedad", compuesto por numerosos registros históricos de entre los que el autor destaca aquellos en los que se anotaba el tiempo atmosférico ${ }^{9}$.

De entre todas las citadas, las fuentes documentales son claramente las menos valoradas por parte de los especialistas que se dedican a la reconstrucción del clima en el pasado por ser aquellas en donde se encierra un mayor grado de subjetividad y por no arrojar éstas resultados tan fiables como las que Behringer ubicaba dentro del "archivo del planeta Tierra".

Precisamente este autor prevenía sobre el peligro que entrañaban los informes de sequías, inundaciones, largos periodos de heladas... en tanto en cuanto no era posible discernir con total seguridad si el autor de dicho informe se refería exclusivamente a un ámbito muy local, si estaba exagerando o si directamente lo que estaba contando era ficción con un significado alegórico ${ }^{10}$.

En esta misma línea, Stéphane Lebecq destaca cómo la historiadora holandesa Elisabeth Gottschalk demostró que todas las tradiciones relativas a las inundaciones anteriores al siglo IX que se citan en la Crónica frisia que publicó Andreas Cornelius en 1597 son falsas ${ }^{11}$.

Especialmente contundente es Juan Carlos García al afirmar que "la principal limitación de este tipo de documentos es que, en general, privilegian lo excepcional sobre lo cotidiano (...) Además, estos datos

9 BEHRINGER, Wolfgang, A Cultural History of Climate, Cambridge, Polity Press, 2010, pp. 8-13.

10 BEHRINGER, Wolfgang, A Cultural History..., p. 13.

11 LEBECQ, Stéphane, "L'homme au péril de l'eau dans les plaines littorales des anciens Pays-Bas au début du Moyen Âge", en BENNASSAR, Bartolomé (ed.), Les catastrophes..., p. 33. Cito a Stéphane Lebecq porque no he podido consultar directamente los trabajos de Elisabeth Gottschalk. 
dependen en su transcripción de la subjetividad del que los recogió que, por un mecanismo natural, tiende a exagerar este tipo de acontecimientos. Por eso, estas fuentes inducen fácilmente a error y son pocas veces verdaderamente útiles para el historiador del clima (con el agravante de que, por su propio estilo, resultan muy atrayentes e incluso divertidas y no siempre resulta fácil renunciar a su inclusión en los diferentes trabajos)"12.

En mi opinión, todas estas reservas son más que comprensibles. No tiene ningún sentido pretender argumentar que una fuente escrita por una o varias personas que, ciertamente, cuentan la realidad bajo su prisma tenga la misma credibilidad que el dato obtenido en un laboratorio, que se convierte en algo puramente objetivo, sin carga de sentimentalismo ni de segundas intenciones.

Con todo, en mi opinión, yerran por completo los que descartan directamente los aportes que el patrimonio documental puede ofrecer para la reconstrucción del clima de nuestro pasado. Es evidente que la documentación puede contener errores, omisiones...; puede incluso llegar a ser falsa y que nos cuente cosas que nunca sucedieron.

Sin embargo, disciplinas como la Paleografía y la Diplomática brindan a los historiadores, geógrafos, documentalistas... elementos más que suficientes para discernir la documentación real de la ficticia, la auténtica de la falsa o de la adulterada y, aun así, no debe olvidarse que en cualquier documento falso pueden encontrarse no pocos indicios de verdad.

No es éste el lugar adecuado para explayarse sobre qué criterios permiten diferenciar la autenticidad de la falsedad de un documento, puesto que esto nos conduciría a un tema completamente diferente. Sin embargo, estoy plenamente convencido de que, si el historiador no peca de ingenuo admitiéndolo todo sin criterio y si realiza bien su trabajo no conformándose con unos pocos ejemplares sino realizando amplias comparaciones con varios diplomas de diferentes ámbitos, estará en condiciones de obtener un beneficio bastante provechoso de lo que le ofrece el patrimonio documental.

El trabajo por hacer es ingente. Hubert Horace Lamb, quien también advertía no obstante de los peligros de las fuentes escritas, expre-

12 GARCÍA CODRÓN, Juan Carlos, Un Clima para la Historia... una Historia para el Clima, Santander, Universidad de Cantabria, 1996, p. 22. 
saba su opinión de que muchos más datos podrían obtenerse de ellas si se hiciera un esfuerzo de organización ${ }^{13}$.

En el caso español, Jorge Olcina y Javier Martín han destacado cómo, pese a la enorme riqueza y abundancia del patrimonio documental de nuestro país, fueron muy escasas las iniciativas que tuvieron lugar antes de la década de los noventa del pasado siglo ${ }^{14}$. En este mismo sentido, se manifestaban los autores que abordaron en 2007 los estudios sobre paleoclimatología en España, destacando el "gran potencial para el desarrollo de la Climatología histórica, con un vasto Patrimonio Histórico Documental" y lamentando que esto sólo ha sido abordado "por iniciativas individuales, muy brillantes, pero sin capacidad para aglutinar grupos de investigación permanentes o un esfuerzo sostenido en la misma línea de trabajo más allá de la actividad del propio autor impulsor"15.

Creo pues que es necesario buscar un equilibrio. Es cierto que las fuentes documentales encierran multitud de datos que pueden conducirnos a engaños y conclusiones erróneas. Sin embargo, en mi opinión, no debe caerse en el extremo de infravalorarlas ni mucho menos de apartarlas de nuestras investigaciones, puesto que, haciendo esto, estaríamos dando la espalda a aquello que nos puede auxiliar más que satisfactoriamente para obtener datos en aquellos contextos a los que no se pueda acceder con las técnicas de laboratorio por falta de evidencias.

Ahora bien, una vez que ha quedado admitida - por lo menos, por mi parte - la plena validez de las fuentes documentales, cabe preguntarse cuáles han sido las más utilizadas por todos aquellos que se dedican a la reconstrucción del clima en el pasado.

Puede decirse que la selección ha sido sobradamente acertada, pero, en mi opinión, incompleta en tanto en cuanto no se han agotado todas las posibilidades que ofrece el patrimonio documental.

13 LAMB, Hubert Horace, Climate, history and the modern world, Londres y Nueva York, Methuen, 1982, p. 74.

14 OLCINA CANTOS, Jorge y MARTÍN VIDE, Javier, La influencia del clima en la historia, Madrid, Arco Libros, 1999, p. 39.

15 CREUS, José; PEÑA, José Luis; BARRIENDOS, Mariano; MORENO, Ana; GONZÁLEZ, Penélope; SANCHO, Carlos; VALERO, Blas; PÉREZ, Augusto; SAZ, Miguel A. y CONSTANTE, Ana, "Los estudios de Paleoclimatología... ", p. 259. 
Visitas pastorales, interrogatorios y catastros son las que destaca Emmanuel Le Roy Ladurie para su trabajo ${ }^{16}$, los Annales son lo más citado por Stèphane Lebecq al hablar de las catástrofes en la Alta Edad Media ${ }^{17}$; crónicas, Annales, anotaciones diversas e historias diocesanas son lo que fundamentan el fantástico trabajo de Pierre Alexandre ${ }^{18}$; los exempla utilizados por los predicadores en sus homilías llamaron la atención de Jacques Berlioz ${ }^{19}$; prácticamente de las mismas fuentes hablaba Horace H. Lamb en su citada monografía sobre este tema ${ }^{20}$.

Más allá de las fuentes narrativas o de los meras anotaciones de acontecimientos históricos con carácter anual, Mariano Barriendos puso de manifiesto con sus trabajos cómo muchas más fuentes podían ser perfectamente utilizables para extractar datos sobre el clima, como por ejemplo, los libros de actas o de acuerdos municipales, las actas de los cabildos catedralicios en las que encontramos abundante información sobre rogativas, fuentes privadas tales como libros de memorias, crónicas, dietarios... ${ }^{21}$.

Efectivamente, creo que Mariano Barriendos se muestra especialmente atinado al demostrar cómo existen muchas más fuentes que las que tradicionalmente se habían utilizado para buscar datos interesantes. Con todo, creo que todavía se puede ir mucho más allá y explorar el patrimonio documental con mayor profundidad puesto que, como intentaré hacer ver, las noticias se encuentran donde menos se esperan.

16 LE ROY LADURIE, Emmanuel, Histoire du climat..., vol. II, p. 249.

17 LEBECQ, Sthèphane, "L'homme au péril de l'eau...", p. 35.

18 ALEXANDRE, Pierre, Le climat en Europe au Moyen Âge. Contribution à l'histoire des variations climatiques de 1000 à 1425, d'après les sources narratives de l'Europe occidentale, París, Éditions de l’Ecole des Hautes Études en Sciences Sociales, 1987.

19 BERLIOZ, Jacques, “La foudre au Moyen Âge. L'apport des exempla homilétiques", en BENNASSAR, Bartolomé (ed.), Les catastrophes..., pp. 165-174.

20 LAMB, Hubert Horace, Climate, history..., p. 73.

21 BARRIENDOS VALLVÉ, Mariano, "La climatología histórica en España. Primeros resultados y perspectivas de la investigación", en GARCÍA CODRÓN, Juan Carlos (coord.), La reconstrucción del clima de época preinstrumental, Santander, Servicio de Publicaciones de la Universidad de Cantabria, 2000, pp. 25-26. 


\section{Algunos fenómenos y Su Reflejo en el patrimonio documental}

\section{1. Sequías}

La bibliografía sobre el impacto que la sequía ha tenido a lo largo del tiempo y, en especial, en las sociedades agrarias anteriores a la industrialización adquiere unas dimensiones tan colosales que requerirían un estudio específico sobre el tema. De igual manera, una lista no menos abultada de publicaciones que abordan la respuesta de los colectivos humanos a esa sequía - en España, especialmente, mediante ceremonias religiosas pro pluvia que pretendían inducir a la divinidad a que provocara la tan deseada lluvia - convertirían este artículo en una sucesión interminable de títulos.

Obviando pues la enorme cantidad de referencias bibliográficas que podrían aportarse en cada apartado y cediendo el protagonismo al patrimonio documental, los estragos de la sequía se perciben ya con claridad en los albaranes de época bajomedieval en los que una persona o un concejo reconocían haber percibido una cantidad de dinero en concepto de compensación por los daños sufridos.

En el caso de la comunidad de aldeas de Daroca (Zaragoza), la especial proliferación de albaranes de los años treinta y cuarenta del siglo XV evidencian un largo periodo de sequías con efectos devastadores a todos los niveles. Así, en septiembre de 1441, el concejo turolense de Singra reconocía no poder afrontar pagos "por la grandissima sequa de cinquo anyos en aquel continuada" 22 .

Si a comienzos de los años treinta ya se dejaba notar y entonces Domingo Ortín, vecino de Villafranca del Campo (Teruel), indicaba en 1433 que no había podido moler ${ }^{23}$, no es hasta el cambio de década cuando se producen los mayores efectos y cuando, entre 1439 y 1441, los documentos hablan de una "diminucion de los vezinos del dito lugar por causas de las muertes" ${ }^{24}$.

22 Archivo Histórico Nacional (en adelante, AHN), Diversos-Comunidades, car. 68 , no 126 .

23 AHN, Diversos-Comunidades, car. 55, nº 107.

24 AHN, Diversos-Comunidades, car. 57, no 133. Este caso concreto, de septiembre de 1441, es un albarán del concejo de Vistabella de Huerva (Zaragoza) en el que se habla de los perjuicios ocasionados por la sequía y de las muertes, si bien ciertamente no se dice en ningún momento con claridad que lo segundo fuera consecuencia 
Si damos un salto a 1492, nos encontramos con uno de los años más importantes de la historia de España al repetirse, desde etapas escolares, lo que supuso el descubrimiento de América por parte de Cristóbal Colón, amén de suponer para muchos el momento de transición entre la Edad Media y la Edad Moderna. La singularidad del año 1492 le ha llevado incluso a contar con estudios íntegramente dedicados a él, elaborados generalmente con el objetivo de analizar dicha transición ${ }^{25}$.

Sin embargo, muy pocas alusiones se han hecho por lo general en todos estos estudios sobre 1492 a la sequía que este año afectaba, por lo menos, a Castilla. Cuando quedaba poco más de un mes para que Colón llegara a América, un enfrentamiento entre las localidades riojanas de Viniegra de Abajo y Mansilla de la Sierra hacía hincapié en la especial dificultad del momento.

Así, al hablar del ganado, un documento de septiembre expresa que "ya sabiamos quand notoria fue la seca de aguas de yervas que ovo e el grand danno que los ganados reçibieron e commo se murieron la maior parte dellos, de tal manera que diz que de treinta e çinco mill cabeças de ganado que diz que avia en el dicho lugar no han quedado doze mill" 26 .

El espacio disponible no permite extenderse mucho más; sin embargo, llegada la Edad Moderna, el patrimonio documental español es excepcionalmente rico a la hora de encontrar testimonios sobre la sequía y su incidencia. Como decía antes, abundan sobre todo las rogativas para provocar la lluvia, no sólo en nuestro país ${ }^{27}$, sino también,

directa de lo primero. Con todo, y aunque probablemente no fuera la única causa, puede establecerse cierta relación entre sequía y mortandad.

25 Entre una larga lista, CAMUSSO, Lorenzo, Guía de viaje a la Europa de 1492: 10 itinerarios por el Viejo Mundo, Madrid, Anaya y Sociedad Estatal para la Ejecución de Programas del Quinto Centenario, 1990; SESMA MUÑOZ, José Ángel; SANVICENTE PINO, Ángel; LALIENA CORBERA, Carlos y GARCÍA HERRERO, Maㅡ Carmen, Un año en la historia de Aragón, 1492, Zaragoza, Caja de Ahorros de la Inmaculada, 1992; MARTINIÈRE, Guy y VARELA, Consuelo, L'etat du monde en 1492, París, La Decouverte, 1992 o FERNÁNDEZ-ARMESTO, Felipe, 1492: el nacimiento de la modernidad, Barcelona, Debate, 2010.

26 Archivo General de Simancas (en adelante, AGS), Registro General del Sello, leg, $149209,126$.

27 Algunas de ellas contaban incluso con la implicación directa de la monarquía, como se ve por ejemplo en un documento de julio de 1608 por el que Felipe III apro- 
considerando lo que era en aquella época el imperio español, de diversos puntos del planeta $^{28}$.

\section{2. Riadas e inundaciones}

No son algo excluyente con respecto a las sequías, sino que coexisten con especial frecuencia. Se trata de algo muy bien estudiado en líneas generales, como podemos ver en el detallado listado de las riadas e inundaciones de los últimos quinientos años en España que publicó Inocencio Font ${ }^{29}$.

Como norma general, la documentación refiere las destrucciones que habían causado dichas riadas y/o inundaciones o aquello que, aunque fuera en los detalles más mínimos, afectaba a la vida cotidiana de la gente. De igual modo, al igual que sucedía con la sequía, los problemas que generaba una especial avenida de agua llegaban incluso a las más altas esferas del poder, como, por ejemplo, cuando en enero de 1345 Pedro IV de Aragón pidió a su oficial real en Collioure (Francia) que le informara de cómo se encontraban las vías de acceso a esta localidad después de que hubieran quedado anegadas "ex inundacione aquarum" ${ }^{\prime 30}$.

Campos inundados, puentes derribados y casas destruidas suelen ser el bagaje que provoca el agua cuando ésta llega en proporciones desorbitadas. Resultan especialmente abundantes los memoriales, peticiones realizadas por los damnificados a las autoridades para que les condonaran o redujeran las contribuciones que debían abonar al haberse arruinado las cosechas o incluso al haber perdido todas sus posesiones.

bó las rogativas que le había encargado el duque de Escalona: Archivo Histórico de la Nobleza (en adelante, AHNob), Frías, c. 25, d. 8.

28 Como detallaré más adelante, es frecuente encontrar información donde menos se espera. Así, por ejemplo, una carta de julio de 1739 en la que el arzobispo de Manila expresaba sus desavenencias con la Audiencia de Filipinas, indica cómo, desde 1737, se estaba produciendo una sequía que había provocado la celebración de rogativas y procesiones para atraer la lluvia: Archivo General de Indias (en adelante, AGI), Filipinas, 291, nำ 32 .

29 FONT TULLOT, Inocencio, Historia del clima..., pp. 65-66 (siglo XV), 79 (siglo XVI), 86-87 (siglo XVII), 103-104 (siglo XVIII), 116-117 (siglo XIX) y 167-169 (siglo $\mathrm{XX)}$.

30 Archivo de la Corona de Aragón (en adelante, ACA), Real Cancillería, Cartas reales, Pedro III [IV], 2629. 
Los documentos suelen ser prolijos en detalles. Por poner un ejemplo, en marzo de 1788, el administrador del marqués de Castromonte (Valladolid) informaba a su señor del desbordamiento del río Esgueva y de "las desgracias acaescidas en esta ciudad y lugares inmediatos, en estos por el aumento de agua que tomaron sus rios y en esta que igualmente tomo la Esgueva que la atraviesa toda, pues ha (sic) quedado arruinados todos los puentes por donde pasaba que eran fuertisimos; muchos undimientos en las calles; y arruinadas y que estan para arruinarse mas de trescientas casas" 31 .

Ciertamente, las riadas e inundaciones, al igual que la sequía, debían de ser el pan nuestro de cada día. Si ya la Edad Media está llena de historias de infraestructuras derribadas como consecuencia de la fuerza del agua, un documento relativo a las más que frecuentes crecidas de los ríos catalanes Galligans, Güell, Oñá y Ter resulta especialmente relevante al informar de cómo éstos se desbordaron en 1728, 1732 , 1733, continuadamente entre 1738 y 1744, 1746 y $1747^{32}$, año este último en el que decidieron tomarse medidas para evitarlas.

\section{3. Viento, tormentas y tempestades}

Especialmente amedrentadora se muestra el agua cuando cae sin medida desde el cielo y ésta viene acompañada de fuertes vientos. Esa misma agua tan deseada en época de sequías y que procuraba atraerse mediante rogativas, se convierte en algo especialmente temido y de gran poder destructivo cuando viene en forma de fuerte tormenta o de tempestad.

El patrimonio documental español se encuentra plagado de noticias de naufragios acontecidos en todo tipo de lugares, tanto en el Mediterráneo como en el Atlántico. Multitud de cartas en las que se dan detalles de la tempestad y en las que se hace mención a las mercancías que se habían ido al fondo del mar nos permiten conocer bastante, además de sobre dichos hundimientos, sobre en qué momentos y lugares se produjeron dichas tormentas de consecuencias catastróficas.

Como es fácil imaginar, el Archivo General de Indias es el que más información ofrece al respecto por los abundantes viajes entre España y América a través del océano Atlántico, a lo que hay que sumar los

31 AHNob, Baena, c. 419, d. 177.

32 AHN, Diversos-Colecciones, 204, nº 1 . 
océanos Pacífico e Índico después del descubrimiento del estrecho de Magallanes en 1520.

La sección de Consejo de Estado del Archivo General de Simancas sobresale de igual modo en la cantidad de fuentes que nos hablan de tormentas y naufragios en tanto en cuanto los responsables de las embarcaciones y/o gobernadores de un territorio debían informar inmediatamente a las autoridades de cualquier incidencia relacionada con las mismas.

Cartas como la que el duque de Tursi (Italia) envió a Felipe IV de España en enero de 1636 informándole de cómo "vino una tormenta tan grande que hiço perder el galeon S. Raymundo de la Armada, que avia aportado aqui, y con ser al amanezer no se pudo socorrer por la gruessa mar y priessa con que sucedio" 33 siguen esperando a que los especialistas las estudien con el detenimiento necesario.

$\mathrm{Al}$ igual que sucedía con anteriores fenómenos meteorológicos, las tempestades llegaban incluso a preocupar a las élites del poder en tanto en cuanto les frustraban sus planes. Un ejemplo sintomático de ello es la preocupación que en septiembre de 1501 mostraba Enrique VII de Inglaterra por el hecho de que la infanta Catalina de Aragón, hija mayor de los Reyes Católicos, no hubiera podido llegar todavía a tierras británicas como consecuencia de una tempestad para contraer matrimonio con el infante Arturo, heredero de la corona inglesa en aquellos momentos ${ }^{34}$.

Las tormentas también son, a menudo, causantes del cambio en el comportamiento de los seres humanos o de las leyes que rigen su modo de vida. Un par de documentos de abril de 1494 contienen la petición que hicieron respectivamente la provincia de Guipúzcoa y el condado de Vizcaya para que en los puertos del reino no se cobraran impuestos a los barcos que atracaran en ellos huyendo de sus enemigos o refugiándose ante una tempestad ${ }^{35}$.

El peligro que supone una tormenta cuando uno se encuentra a la intemperie es algo que también se refleja en la documentación. El Archivo Histórico de la Nobleza (Toledo) se erige aquí como un depósito más que destacado de referencias documentales en tanto en cuanto en él se albergan las peticiones que agricultores y ganaderos

33 AGS, Consejo de Estado, leg, 3593, 75.

34 AGS, Patronato Real, leg. 53, doc. 42.

35 AGS, Registro General del Sello, leg, 149404, 376 y 377. 
afectados hacían a sus respectivos señores a fin de que éstos les redujeran sus impuestos.

Especialmente llamativo resulta el memorial que Manuel Chacón y Juan Mejía, vecinos de Ciudad Real, presentaron en 1813 al duque del Infantado informándole de que, en un escenario muy devastado por los enfrentamientos acontecidos durante la Guerra de la Independencia, yendo con sus rebaños por el monte, les había sorprendido una tormenta que les había obligado a buscar refugio en una cuadra cuando "principio a arder la techumbre y a desprenderse sobre los supplicantes y ganaderos maderos encendidos que los dispiertan (sic) el asombro que causaba la boracidad de las llamas agitadas por el viento" 36 .

Los efectos del viento son algo que tampoco han pasado desapercibidos en la documentación. Prescindiendo de lo relativo a los naufragios por haberse aludido ya a ellos, el viento es también el principal culpable de extravíos, de alteraciones de rutas marítimas o de multitud de contratiempos como los militares que vieron en 1794 cómo todas sus tiendas quedaban destrozadas ${ }^{37}$ o como, por ejemplo, le sucedió a Pedro Godínez, vecino de Baeza, a quien el viento en contra desvió su barco en 1495 provocando que le robaran todo cuanto llevaba ${ }^{38}$.

\section{4. Terremotos y maremotos}

Más allá de los fenómenos meteorológicos que podríamos denominar como habituales y dejando aparte también los casos más famosos, no hay muchas referencias en el patrimonio histórico español a erupciones volcánicas ocurridas en territorio nacional ${ }^{39}$. No sucede, sin embargo, lo mismo con respecto a noticias de terremotos y de maremotos, de los

36 AHNob, Osuna, ct. 189, d. 128.

37 AHNob, Osuna, ct. 203, d. 139.

38 AGS, Registro General del Sello, leg, 149505, 238.

39 Quizá el ejemplo más llamativo sea lo que Cristóbal Colón describió en agosto de 1492, poco antes de partir hacia América; véase CARRACEDO GÓMEZ, Juan Carlos; RODRÍGUEZ BADIOLA, Eduardo; PÉREZ TORRADO, Francisco José; HANSEN MACHÍN, Álex; RODRÍGUEZ GONZÁLEZ, Alejandro; SCAILLET, Stephane; GUILLOU, Hervé; PATERNE, Martine; FRA PALEO, Urbano y PARIS, Raphäel, “La erupción que Cristóbal Colón vio en la isla de Tenerife (Islas Canarias)", Geogaceta, 41 (2007), pp. 39-42. 
que encontramos diversas menciones que, por lo general, han sido ya utilizadas por los historiadores.

Los terremotos acontecidos en la mitad sur peninsular han dejado su reflejo en la documentación, siendo quizá el ocurrido en Málaga en enero de 1494 el primero de los más relevantes. Una vez más con las máximas autoridades implicadas en el asunto, los propios Reyes Católicos encargaron en junio de este año a Juan Alonso Serrano, su corregidor en esta ciudad, que supervisara la labor que se le había encargado a los musulmanes en la reparación de castillo de Almogía después de que hubiera quedado parcialmente destruido por dicho terremoto ${ }^{40}$.

Famosos algunos de estos terremotos como el que tuvo lugar de nuevo en Málaga en 1680 o el que afectó a Lisboa en 1755, Bernard Vincent es autor de un completo y valioso cuadro en el que anota los seísmos acontecidos en España y Portugal entre los años 881 y 1798, obteniéndose con ello una visión panorámica bastante profunda del tema ${ }^{41}$.

Sin embargo, una vez más, el patrimonio documental español no queda limitado a la obtención de noticias de España, sino que su alcance se hace extensible al resto del planeta, como puede verse, por destacar un par de ejemplos, en la carta que el duque del Infantado recibió en agosto de 1688 informándole del terremoto que había asolado toda la región italiana de Calabria ${ }^{42}$ o como el acontecido en Arequipa (Perú) en 1784 y, más concretamente, "el dia 13 de mayo anterior a las siete y quarto de su mañana" ${ }^{\prime 3}$.

Quedaría añadir en este tema que, en realidad, raramente nos encontramos con un fenómeno único, sino que unos suelen desencadenar otros. De la misma manera que una tormenta generaba el incendio de una techumbre en uno de los casos vistos anteriormente, una hoja de papel suelta del fondo del ducado de Osuna relata cómo, en un momento indeterminado, la isla de Jamaica sufrió inundaciones provocadas por un maremoto, además de un incendio por el fuego arrojado por un volcán marino que causó más de siete mil muertos ${ }^{44}$.

40 AGS, Cámara de Castilla, Cédulas, 1, 52, 1.

41 VINCENT, Bernard, "Les tremblements de terre en Espagne et au Portugal", en BENNASSAR, Bartolomé (ed.), Les catastrophes..., pp. 77-94.

42 AHNob, Osuna, ct. 96, d. 41.

43 AGI, Lima, 666, no 28.

44 AHNob, Osuna, ct. 198, d. 100. 
Es muy posible, en especial en este último caso, que todos estos documentos contengan exageraciones y ahí los historiadores deben intentar calibrar qué puede ser real y qué no en función de si los hechos a los que se alude se mencionan o no en otras fuentes. En todo caso, no puede negarse que el patrimonio documental contiene multitud de referencias y datos que todavía esperan a ser procesados por los especialistas.

\section{Conclusiones}

Como he ido adelantado, nuestra aproximación al patrimonio documental no puede ni debe ser excesivamente reduccionista ni debemos conformarnos con las fuentes típicas utilizadas por prácticamente todos, tales como Annales, crónicas, rogativas pro pluvia... El abanico es mucho más amplio, tal y como creo que ha quedado demostrado en las páginas anteriores.

Quienes quieran aproximarse a la reconstrucción del clima en el pasado o a los efectos que éste tuvo en la sociedad tampoco deben conformarse con buscar los datos en los resúmenes de los documentos que aparecen en los inventarios y catálogos de cada archivo, sino que deben sumergirse de lleno en pergaminos y papeles a fin de encontrar lo que no siempre es evidente.

A este respecto, me parecen especialmente indicativos de lo que afirmo un par de casos.

El primero de ellos es un libro registro de la Universidad de Alcalá de Henares del siglo XVIII en el que se anotaron las faltas de asistencia de los catedráticos desde finales de la centuria anterior, los nombres de los sustitutos, el número de horas que cada uno faltó a clase y las multas que les fueron impuestas por dicha ausencia. El tema no tiene nada que ver con lo que nos ocupa ni nada parece revelar que se vaya a hablar de otra cuestión hasta que el lector llega al folio 395v. y descubre un par de hojas en las que se incluye una narración sobre las procesiones dedicadas a la Virgen y las rogativas que se hicieron para paliar la sequía entre 1750 y $1754^{45}$.

El segundo caso, publicado por Miriam Fernández en su Trabajo Fin de Máster sobre la documentación inédita de Sancho IV que se custodia en el Archivo Histórico de la Nobleza, consiste en una conce-

45 AHN, Universidades, 1. 417, fols. 395v.-397v. 
sión que este monarca hizo en febrero de 1289 a su escribano real, Pedro Sánchez, de sesenta pobladores para el lugar de San Pedro de Palmiches (Cuenca). Cuando se examina el pergamino con detenimiento, nos encontramos la mención a un puente que había sido derribado por una riada: "para faser la puente que solia y ser, que se levo el rio, e para adobarla, que tome Pero Sanches..."46.

Como se ve, la reconstrucción del clima en el pasado es algo que, si bien quizá no exclusivamente, en gran medida puede y debe hacerse teniendo en cuenta el patrimonio documental. Es cierto que éste, en ocasiones, está cargado de inexactitudes y repleto hasta incluso de falsedades y esto es algo que tampoco podemos ignorar.

Sin embargo, con el necesario juicio crítico que lleva a los historiadores a discernir lo real de lo inventado y a diferenciar los documentos auténticos de los falsos - no sin cierto margen de error, todo debe reconocerse-, creo que el patrimonio documental encierra multitud de datos que todavía quedan por ser descubiertos, organizados, enjuiciados, sistematizados, analizados, contrastados y posiblemente también descartados.

No pretendo poner en tela de juicio ninguna investigación realizada en el pasado, pero creo que, gracias al patrimonio documental, quedan todavía muchas cosas por descubrir sobre el clima y muchas páginas por escribir.

\section{Apéndice documental}

1441, septiembre, 14

Langa del Castillo (Zaragoza)

Domingo Sebastián, jurado de Singra, reconoce haber recibido de Antón Sánchez del Romeral, vecino de Burbáguena, trescientos sueldos jaqueses como ayuda para el pago de la pecha que no podían atender a causa de una sequía de cinco años continuos. Archivo Histórico Nacional, Diversos-Comunidades, car. 68, no 126.

Manifiesto sia a todos que yo Domingo Savastian, menor de dias, vezino e jurado del lugar de Singra, aldea de la / ciudat de Darocha, en el dito nom-

46 FERNÁNDEZ PÉREZ, Miriam, Documentación inédita de Sancho IV (1284-1295) en el Archivo Histórico de la Nobleza (Toledo), Universidad de Cantabria, 2018, p. 65. Trabajo Fin de Máster. Agradezco a la autora su autorización para hacer mención de un contenido que, en el momento de redacción de estas líneas, es de acceso restringido. 
bre atorgo haver havido e contantes en poder mio recebido de vos, el honorable don / Anthon Sanchez del Romeral, vezino del lugar de Burvaguena, scrivano de la comunidat de las aldeas de la dita ciudat, / trezientos sueldos dineros jaqueses, buena moneda corrible en Aragon, los quales al dito lugar fueron provey/dos por via de suplicacion en plega general ultimament fecha en el lugar de Romanos, clamada de Sant Miguel, / en ayuda de la pecha, la qual buenament no podiamos pagar por la grandissima sequia de cinquo anyos en aquel / continuada.

E porque de los ditos trezientos sueldos me atorgo seyer pagado, renunciant a to/da excepcion de frau e de enganyo e de no haver havido e non recebido contantes en poder mio los ditos tre/zientos sueldos en el dito nombre, fago vos end fer el present publico albaran a todos tiempos firme e valedero. /

Feyto fue aquesto en el lugar de Langa, a quatorze dias del mes de setiembre anno a Nativitate Domini mi/llesimo quadringetesimo quadragesimo primo.

Presentes testimonios son de aquesto Martin Berruequo e Gui/ralt Sanchez del Romeral, vezinos, habitadores del lugar de Burbaguena.

Sig(signo)no de mi Johan Siscar, vezino del lugar de Fuentesclaras, por actoridat real nota/rio publico en los regnos de Aragon e de Valencia, qui a las sobreditas cosas present fue e aquesto screvi e çerre.

\section{2}

1494, junio, 17

Medina del Campo

Los reyes Fernando e Isabel encargan a Juan Alonso Serrano, corregidor de Málaga, que supervisara la labor que se les había encargado a los musulmanes en la reparación de castillo de Almogía después de que hubiera quedado parcialmente destruido por el terremoto de enero.

Archivo General de Simancas, Cámara de Castilla, Cédulas, 1, 52, 1.

El rey e la reyna.

Bachiller Juan Alonso Serrano, nuestro corregidor de la çibdad de Malaga e / otras qualesquier nuestras justiçias de la dicha çibdad. /

Nos somos ynformados que la noche que tenblo la tierra / en el mes de enero deste presente anno derribo algunos / pedaços de lienços e torres e almenas de la forta/leza de Almoxia, lo qual es necesario < de > se reparar / e, porque los moros de la dicha villa de Almoxia dis que son / obligados de fer parte del dicho reparo e nos vos mandamos / que vos ynformes de lo que los dichos moros son obligados / de fer e les conpelays e apremies a que lo hagan e cumplan / luego dandoles para ello el termino que vos pa- 
reçiere / rasonable en que lo puedan fer. E nos enbiad relaçion / de lo que mas fuere menester.

E non fagades ende al.

Fecho / en Medina del Campo, a dies e siete dias del mes de junio / de noventa e quatro anos.

Yo el rey. Yo la reyna.

Por mandado del rey e de la reyna, Fernad (sic) Alvares.

1776, junio, 13

Valladolid

Juan de la Espada y diversos vecinos de Mirabel solicitan al marqués de Algarinejo una rebaja en las rentas que debían pagar por el trigo a causa de las pérdidas ocasionadas en las cosechas por las heladas.

Archivo Histórico de la Nobleza, Luque, c. 564, d. 174.

Señor marques de Algarinejo y Cardeñosa:

Señor:

Juan de la Espada y consortes, vecinos y labrado/res de la villa de Miravel, en la presencia de Vuestra Señoria, / con el maior respeto dicen que los suplicantes son / arrendadores de la lavor de la dehesa de Valsalgado, / propia de Vuestra Señoria, con obligacion de pagar doscientas y / treinta fanegas de trigo de terrazgo de la (cosa?) del / presente año de mil setecientos setenta $\mathrm{y}$ seis, $\mathrm{y}$, / con motibo de la perdida que experimentaban en dicho / sembrado á causa de unos fuertes yelos que caieron, / án ocurrido los suplicantes a don Josef Blanco, / administrador de las rentas de Vuestra Señoria en esta ciudad a fin / de que nombre una persona practica que le reconozca / y en su vista le haga el rebajo correspondiente a la / gran perdida que esperimentan y, como dicho / administrador haia respondido de que se haga presente á / Vuestra Señoria para que se sirba tomar la providencia que / fuese de su agrado, ocurren a la gran piedad de Vuestra Señoria / suplicando se sirva haver de piedad con los suplicantes y man/dar le reconozca dicho sembrado $\mathrm{y}$, segun lo que resulte de la / declaracion del perito, mandar se haga la vaja correspondiente / de dicho terrazgo.

Como así lo esperan de la gran justicia / de Vuestra Señoria, cuia vida guarde Dios muchos años.

$\mathrm{Pla} / /$ sencia y junio 13 de mil setecienttos (sic) / setenta y seis.

Besando las manos de Vuestra Señoria, sus mas rendidos servidores, / por si y demas consortes.

Juan de la Espada. 
1788, marzo, 1

Valladolid

Francisco Javier de Matesanz, administrador del marqués de Castromonte, le informa de los desastres causados por la crecida y desbordamiento del río Esgueva. Archivo Histórico de la Nobleza, Baena, c. 419, d. 177.

Excelentisimo señor, mi señor ${ }^{47}$ :

Señor:

No puedo menos, aunque con harto sen/sentimiento (sic), manifestar a Vuestra Excelencia las desgra/cias acaescidas en esta ciudad y luga/res inmediatos, en estos por el aumento de / agua que tomaron sus rios y en esta / que igualmente tomò la Esgueva que la / atraviesa toda, pues ha (sic) quedado ar/ ruinados todos los puentes por donde pa/saba que eran fuertisimos; muchos un/dimientos en las calles; y arruinadas y que / estàn para arruinarse mas de tres/cientas casas, pero no ha tocado nada / de esto à las de Vuestra Excelencia por hallarse / en distinto sitio y mas altura que el / por donde pasaba la Esgueva, de modo / que ha quedado el pueblo enteramente des/truido è intransitable.

En el sitio de la barca, que es / el rio Duero, inmediato à la villa de / Tudela, en esta se ha llevado asegu/ran que mas de noventa casas y las / bodegas que estaban fuera del pueblo. La barca parece se livertò à costa / de haber perdido la vida uno de los // criados del barquero, y otro quedado / mui mal tratado; pero la maroma, / linos y tornos donde se hallava pues/ta aquella, con la casilla que se hizo / nueva hace quatro ò cinco años, todo lo sacò de la tierra y llevó el rio y / lo mismo el puente que habia un quar/to de legua mas allá de este paso, de / modo que ha hecho de daño a Vuestra Excelencia mas / de quatrocientos ducados que seran nece/sarios para volver à poner dicho paso / corriente.

En Medina del Campo no tengo / razon todavia de si ha perecido alguno / de las casas, sobre las quales tiene Vuestra Excelencia censo perpetuo; darè aviso luego que / le tenga y en el interin quedo à / la respuesta de Vuestra Excelencia con el mayor rendimiento, / pidiendo a Nuestro Señor guarde a Vuestra Excelencia / en su mayor grandeza los dilatados / años que puede y necesito.

(Margen izquierdo: Valladolid y marzo $1^{\circ}$ de 1788).

Francisco Xavier de Matesanz.

47 El destinatario consta en la parte inferior del reverso, debajo de la firma del autor: "Excelentisimo señor de Castromonte, Mi Señor". 
1794, julio, 29

La Habana (Cuba)

Luis de las Casas, capitán general de Luisiana, informa de las inundaciones sufridas en Mobile y en Feliciana.

Archivo General de Simancas, Secretaría de Estado y del Despacho de Guerra, leg, 6916, 34 .

Excelentisimo señor ${ }^{48}$ :

Con carta de 30 de abril ultimo me remi/te el governador de la Nueva Orleans copias / de las que recivió de los comandantes de Mo/vila y Feliciana $\mathrm{y}$ de sus contextaciones so/bre una inundacion que han padecido aque/llos nuevos establecimientos con perdida de / muchos animales, viveres y parte de las ca/sas, con cuyo motivo dice ha socorrido a los / desgraciados con 200 barriles de maiz en / espiga, costeados de los fondos de Poblacion, / y concluye pidiendome de qüenta a Su Majestad para / su real aprovacion, a cuyo fin lo partici/po a Vuestra Excelencia con copia de las predichas cartas.

Dios guarde a Vuestra Excelencia muchos años.

Havana, 29 / de julio de 1794.

Excelentisimo señor, Luis de las Casas.

\section{6}

1813, junio, 14

Ciudad Real

Manuel Chacón y Juan Mejía, vecinos de Ciudad Real, exponen que, yendo con el ganado, les sorprendió una tormenta que les obligó a refugiarse en una cuadra, de la cual se incendió la techumbre como consecuencia de un rayo.

Archivo Histórico de la Nobleza, Osuna, ct. 189, d. 128.

Excelentisimo señor duque del Ynfantado:

Manuel Chacon y Juan Mejía, vecinos de Ciudad / Real, capital de la provincia de la Mancha, a Vuestra Excelencia con el mas / profundo respeto y confianza recurren por tercera bez y / dicen:

Que despues de la asombrosa borrasca y persistencia / asoladora de los exercitos franceses sobre dicha provincia y despues / del horrible saqueo y uberajes que han recivido la casa y / familia de los exponentes, para salir de la miseria en / que se beian sumergidos, hicieron un esfuerzo fuera de / la costumbre de su trafico y acopiando y acojiendo / de otros vecinos un corto

48 El destinatario consta en la esquina inferior izquierda del papel: "Excelentisimo señor conde / del Campo de Alange". 
numero de ganado de cerda, / se deliberaron a tomar el fruto de vellota de dos milla/res en el real valle de Alcudia que disfrutan los ganados / de Vuestra Excelencia llamados aquellos Mochuelos y Loma del Toril / y, acopiando los bastimentos necesarios para la temporada, / se dirijieron los esponentes a buscar la suerte consola/dora de sus familias.

Establecidos asi en los quintos, / economizaban los frutos para estraer toda bentaja y un / dia aciago por todos respetos, se lebantan aguaceros, // formase una celisca repentina y, azotando el viento / a el agua, acobardaron el ganado, todo el de cria / quedo a punto de perecer y los exponentes en igual riesgo / deliveraron acojerse a una quadra independiente de la / casa que llaman del Ato propia de Vuestra Excelencia, la misma que con / motibo de las partidas y franceses estaban desechos los / pesebres y franca la puerta.

Guarecidos los que espo/nen en un albergue tan oportuno, se contaban por menos infelizes, pero a poco rato de haverse reclinado / a pasar la noche y a pesar de quedar la lumbre / recogida, principio a arder la techumbre y a des/prenderse sobre los supplicantes y ganaderos maderos / encendidos que los dispiertan (sic) el asombro que causaba / la boracidad de las llamas agitadas por el viento.

En tal conflicto y biendo el inminente peligro de / sus vidas, se arrojaron al campo contentos con salbarlas y fueron espectadores de un fuego irreme/ diable; ardio la techumbre y bajo de ella se sepul/taron los bastimentos que con mil afanes tenian / acopiados para la subsistencia de la temporada.

$\mathrm{Y}$ en estas circunstancias, quando eran dignos de toda / commiseracion, el apoderado de Vuestra Excelencia don Manuel / Sanz de Vergara, cumpliendo con su deber, quiere exigirles el costo de la techumbre que, aunque no / de mucha consideracion, pues sera poco mas de catorce baras de largo y todo de maderas toscas de monte, sin embargo para los supplicantes es de // mucha entidad por su estado decadente y porque / sus facultades con tantos contratiempos como la / desgracia les prepara se ben muy reducidas.

Por estas fuertes consideraciones y respecto a que los / exponentes al tiempo de introducir sus ganados / en los espresados quintos prestaron las correspondientes / fianzas de estilo que tiene retenidas el espresado / apoderado, litan que satisfagan el importe de la techumbre quemada con el fin de que no insista / en querer exijirsele a pesar de haverle mani/festado haver acudido a Vuestra Excelencia como con efecto / lo han practicado reverentemente hasta por tercera bez para que se digne resolver en el / particular, acercandose nuebamente la pe/queñez de los que exponen a implorar la benignidad propia de su grandeza. 
Supplican a Vuestra Excelencia rendidamente se sirba livrar / su orden al esplicado apoderado para que, dejan/do libres las fianzas de los que representan, / no les moleste, estando prontos a hacer por / su mano y para ayuda a la reedificacion del / tejado el corte y entalle de las maderas / necesarias, pero quando no sea esto del / agrado de Vuestra Excelencia sacrificaran toda su pobreza / en cumplimiento de una obligacion a que // fueron conducidos por una necesidad irresistible / y por un imprebisto acontecimiento nunca sugeto / a los alcanzes de la prudencia mas prespicaz (sic) / y medida.

Todo asi lo esperan de Vuestra Excelencia y su / relebante y notoria beneficencia.

Ciudad Real, y junio 14 de 1813.

Excelentisimo señor, a Vuestra Excelencia supplican rendidamente:

Manuel Chacon. Por ausencia de mi avuelo, Julian Megia.

\section{Bibliografía}

ALEXANDRE, Pierre, Le climat en Europe au Moyen Âge. Contribution à l'histoire des variations climatiques de 1000 à 1425, d'après les sources narratives de l'Europe occidentale, París, Éditions de l'Ecole des Hautes Études en Sciences Sociales, 1987.

BARRIENDOS VALLVÉ, Mariano, "La climatología histórica en España. Primeros resultados y perspectivas de la investigación", en GARCÍA CODRÓN, Juan Carlos (coord.), La reconstrucción del clima de época preinstrumental, Santander, Servicio de Publicaciones de la Universidad de Cantabria, 2000, pp. 15-56.

BEHRINGER, Wolfgang, A Cultural History of Climate, Cambridge, Polity Press, 2010.

BERLIOZ, Jacques, “La foudre au Moyen Âge. L'apport des exempla homilétiques", en BENNASSAR, Bartolomé (ed.), Les catastrophes naturelles dans l'Europe médiévale et moderne, Toulouse, Presses Universitaires du Mirail, 1996, pp. 165-174.

CARRACEDO GÓMEZ, Juan Carlos; RODRÍGUEZ BADIOLA, Eduardo; PÉREZ TORRADO, Francisco José; HANSEN MACHÍN, Álex; RODRÍGUEZ GONZÁLEZ, Alejandro; SCAILLET, Stephane; GUILLOU, Hervé; PATERNE, Martine; FRA PALEO, Urbano y PARIS, Raphäel, "La erupción que Cristóbal Colón vio en la isla de Tenerife (Islas Canarias)", Geogaceta, 41 (2007), pp. 39-42, [consulta: 12 de julio de 2018], disponible: http://rabida.uhu.es/dspace/handle/10272/8494

COOK, Edward R., "Megadroughts, ENSO, and the Invasion of Late-Roman 
Europe by the Huns and Avars", en HARRIS, William V. (ed.), The Ancient Mediterranean Environment between Science and History, Leiden-Boston, Brill, 2013, pp. 89-102.

CREUS, José; PEÑA, José Luis; BARRIENDOS, Mariano; MORENO, Ana; GONZÁLEZ, Penélope; SANCHO, Carlos; VALERO, Blas; PÉREZ, Augusto; SAZ, Miguel A. y CONSTANTE, Ana, "Los estudios de Paleoclimatología en España", en CUADRAT PRATS, José María y MARTÍN VIDE, Javier (eds.), La Climatología española. Pasado, presente y futuro, Zaragoza, Prensas Universitarias de Zaragoza, 2007, pp. 249-262.

DUCELLIER, Alain, “Les tremblements de terre balkaniques au Moyen Âge: aspects matériels et mentaux", en BENNASSAR, Bartolomé (ed.), Les catastrophes naturelles dans l'Europe médiévale et moderne, Toulouse, Presses Universitaires du Mirail, 1996, pp. 61-76.

FERNÁNDEZ PÉREZ, Miriam, Documentación inédita de Sancho IV (12841295) en el Archivo Histórico de la Nobleza (Toledo), Universidad de Cantabria, 2018. Trabajo Fin de Máster.

FONT TULLOT, Inocencio, Historia del clima de España. Cambios climáticos y sus causas, Madrid, Instituto Nacional de Meteorología, 1988.

GARCÍA CODRÓN, Juan Carlos, Un Clima para la Historia...una Historia para el Clima, Santander, Universidad de Cantabria, 1996.

KLINGAMAN, William K. y KLINGAMAN, Nicholas P., The year without summer: 1816 and the volcano that darkened the world and changed History, Nueva York, St. Martin's Press, 2013.

LAMB, Hubert Horace, Climate, history and the modern world, Londres y Nueva York, Methuen, 1982.

LE ROY LADURIE, Emmanuel, Histoire du climat depuis l'an mil, París, Flammarion, 1983, 2 vols.

LEBECQ, Stéphane, “L'homme au péril de l'eau dans les plaines littorales des anciens Pays-Bas au début du Moyen Âge", en BENNASSAR, Bartolomé (ed.), Les catastrophes naturelles dans l'Europe médiévale et moderne, Toulouse, Presses Universitaires du Mirail, 1996, pp. 27-42.

OLCINA CANTOS, Jorge y MARTÍN VIDE, Javier, La influencia del clima en la historia, Madrid, Arco Libros, 1999.

PARKER, Geoffrey, El siglo maldito. Clima, guerras y catástrofes en el siglo XVII, Barcelona, Planeta, 2013.

RÜTHER, Andreas, "The role of climate and famine in the Medieval Eastern expansion", en COLLET, Dominik y SCHUH, Maximiliam (eds.), Famines during the 'Little Ice Age' (1300-1800). Socionatural entanglements in premodern societies, Cham, Springer, 2018, pp. 133-147.

VINCENT, Bernard, "Les tremblements de terre en Espagne et au Portugal", 
en BENNASSAR, Bartolomé (ed.), Les catastrophes naturelles dans l'Europe médiévale et moderne, Toulouse, Presses Universitaires du Mirail, 1996, pp. 77-94. 
